\title{
Electrode and chemical reactions during electrodeposition of tantalum products in $\mathrm{CsCl}$ melt
}

\author{
V.V. Grinevitch ${ }^{\mathrm{a}, 1}$, S.A. Kuznetsov ${ }^{\mathrm{b}, \mathrm{d}, *}$, A.A. Arakcheeva ${ }^{\mathrm{a}, \mathrm{c}}$, \\ T.V. Olyunina ${ }^{\mathrm{a}}$, A. Schønleber ${ }^{\mathrm{c}}$, M. Gaune-Escard ${ }^{\mathrm{d}}$ \\ ${ }^{a}$ Baykov Institute of Metallurgy and Materials Science RAS, Leninsky Prospect 49, 119991 GSP-1 Moscow, Russia \\ ${ }^{\mathrm{b}}$ Institute of Chemistry Kola Science Centre RAS, 184200 Apatity, Murmansk Region, Russia \\ ${ }^{\mathrm{c}}$ Institut de Crystallographie, Université de Lausanne, BSP-Dorigny, CH-1015 Lausanne, Swizerland \\ ${ }^{\mathrm{d}}$ Ecole Polytechnique Universitaire de Marseille, IUSTI-CNRS UMR 6595, Université de Provence, \\ F-13453 Marseille Cedex 13, France
}

Received 3 November 2005; received in revised form 27 March 2006; accepted 27 March 2006

Available online 21 June 2006

\begin{abstract}
This work was accomplished in the context of systematic examination of a role played by electrolyte cation composition in electroreduction processes. The electrochemical behaviour of molten salts systems where $\mathrm{CsCl}$ was used as solvent for potassium and caesium oxyfluorotantalates was investigated. In particular, the influence of the electrolysis parameters, such as concentration of tantalum species in electrolyte, temperature and current density on the cathodic products phase composition was determined by X-ray diffraction and scanning electron microscopy. Several phases generally crystallized at the cathode simultaneously. Among identified phases were metallic tantalum in cubic $(\alpha)$ and tetragonal $(\beta)$ crystal modifications and $\mathrm{TaO}$. But the most characteristic phases for the melt under study were two isostructural compounds with pyrochlor type crystal lattice $\mathrm{CsTa}_{2+z} \mathrm{O}_{5+y} \mathrm{~F}_{1-y}$ and $\mathrm{CsTa}_{2+z}{ }^{5-x} \mathrm{O}_{5+y} \mathrm{~F}_{1-y}$. The former deposited in the form of transparent dielectric crystals and the later - in the form of metal-like conductive ones. This latter compound seems to be synthesized for the first time. The peculiarities of its structure were described. Electrochemical redox processes in melts containing potassium oxyfluorotantalates dissolved in $\mathrm{CsCl}$ were studied by cyclic voltammetry. Three discharge peaks were detected on voltammograms in the temperature range $700-850{ }^{\circ} \mathrm{C}$. They were associated with the discharge of $\mathrm{TaOF}_{6}{ }^{3-}$ and $\mathrm{TaO}_{2} \mathrm{~F}_{4}{ }^{3-}$ complexes and alkali metal cations.
\end{abstract}

(C) 2006 Published by Elsevier Ltd.

Keywords: Tantalum; Molten salts; Electrocrystallization; Electrode processes; Crystal structure

\section{Introduction}

Electrolysis of a simple molten system containing a halide of refractory metal and an alkali metal halides mixture results in cathodic deposition of refractory metal in a very wide range of electrolysis parameters. Such systems are utilized usually for the electrochemical refining of these metals.

If the electrolysis is performed using more complex systems such as ones including oxygen-containing complex ions, the deposition of a great variety of compounds is possible [1-4]. The phase composition of cathode products may be controlled

\footnotetext{
${ }^{*}$ Corresponding author. Tel.: +7 81555 79730; Fax: +7 8155561658 .

E-mail address: kuznet@chemy.kolasc.net.ru (S.A. Kuznetsov).

${ }^{1}$ Deceased.
}

in this case by varying parameters of the electrochemical process, such as: temperature, current density, chemical form and concentration of basic metal species, anion and cation composition of solvent. The influence of all these parameters with the exception of the latter on the mechanism of electrochemical processes has been adequately covered in the literature [4].

As for the solvent cation composition its role in electrochemical processes remained out of the focus. This may explain the limited and often nonfunctional choice of solvent employed in electrochemical researches, most of the time the equimolar $\mathrm{KCl}-\mathrm{NaCl}$ mixture or the ternary $\mathrm{LiF}-\mathrm{NaF}-\mathrm{KF}$ eutectic (FLINAK). However, in many cases such a simplified approach to the choice of a solvent selection restricts the amount of information that could be obtained from electrochemical studies. From electrochemical point of view of the above-listed salt systems are essentially mixtures of several halides in random 
combination. Their using removes the possibility to determine the specific role played by each outer-sphere cation of the solvent in an electrochemical process. Meanwhile, our study of niobium-containing salt systems $[5,6]$ showed that this role may be very important and even decisive. It was demonstrated that varying the outer-sphere cation composition is a powerful tool to control the chemical and phase composition of electrolysis products. Thus, only the substitution of sodium for a larger cation $\left(\mathrm{K}^{+}\right.$, for example) in the fluoride solvent for $\mathrm{K}_{2} \mathrm{NbOF}_{5}$, other condition being invariable, entailed the oxygen content in the cathodic deposit to be decreased from 14 to $16 \mathrm{wt} \%$ to hundredths of one percent, while their phase composition changed from $\mathrm{NbO}$ to pure $\mathrm{Nb}$ metal [7]. There is a possibility to synthesize novel low valence niobium compounds with layered structures when $\mathrm{KF}$ and $\mathrm{RbF}$ melts are used as solvent, but similar phases could not be obtained with $\mathrm{LiF}, \mathrm{NaF}$ or $\mathrm{CsF}$ as solvents.

On might expect that in tantalum-containing oxyhalide melts outer-sphere cations would play also an important role, because $\mathrm{Nb}$ and $\mathrm{Ta}$ are chemical analogues. This was demonstrated previously in [8]. The present work is the first part of a systematic study of cation composition effect on the electrolysis mechanism in tantalum oxyfluoride-chloride and oxyfluoride-fluoride melts. It is devoted to the electrochemical behaviour of molten salt systems where $\mathrm{CsCl}$ is used as solvent for tantalum oxyfluoride complexes.

\section{Experimental}

Potassium and caesium heptafluorotantalates $\mathrm{K}_{2} \mathrm{TaF}_{7}$ and $\mathrm{Cs}_{2} \mathrm{TaF}_{7}$, potassium and caesium monooxyfluorotantalates $\mathrm{K}_{3} \mathrm{TaOF}_{6}$ and $\mathrm{Cs}_{3} \mathrm{TaOF}_{6}$, potassium dioxyfluorotantalate $\mathrm{K}_{3} \mathrm{TaO}_{2} \mathrm{~F}_{4}$ were used as tantalum-containing components of electrolytes. To produce these salts, high-purity tantalum pentaoxide, prepared in the laboratory by calcination of electrolytically refined tantalum metal in air at $1100{ }^{\circ} \mathrm{C}$, was dissolved in chemically pure $50 \mathrm{wt} . \%$ hydrofluoric acid in a teflon vessel. The precipitation of $\mathrm{K}_{2} \mathrm{TaF}_{7}$ or $\mathrm{Cs}_{2} \mathrm{TaF}_{7}$ was initiated by addition of a saturated solution of potassium or caesium fluorides, respectively, at $80^{\circ} \mathrm{C}$. The product was filtered, washed with rectified ethanol and dried under vacuum at $60^{\circ} \mathrm{C} . \mathrm{K}_{3} \mathrm{TaOF}_{6}, \mathrm{Cs}_{3} \mathrm{TaOF}_{6}$ and $\mathrm{K}_{3} \mathrm{TaO}_{2} \mathrm{~F}_{4}$ synthesis were performed by melting $\mathrm{K}_{2} \mathrm{TaF}_{7}$ or $\mathrm{Cs}_{2} \mathrm{TaF}_{7}, \mathrm{Ta}_{2} \mathrm{O}_{5}$ and $\mathrm{KF}$ or $\mathrm{CsF}$ in appropriate ratios in a glassy carbon vessel under argon atmosphere.

"Spectrally" pure caesium chloride was used. To remove any residual moisture, the salt was heated under vacuum (2 Torr) with a slow stepwise temperature increase up to $500^{\circ} \mathrm{C}$, and then melted in a platinum crucible under argon. Caesium fluoride was prepared from commercial $\mathrm{CsHF}_{2}$ ("chemically pure") by removal of $\mathrm{HF}$ at $600^{\circ} \mathrm{C}$ under argon atmosphere in a platinum crucible.

Voltammetric studies were conducted in a three-electrode cell using a VoltaLab-40 potentiostat with packaged software "VoltaMaster 4 version 6". The potential scan rate was varied between 50 and $300 \mathrm{mV} \mathrm{s}^{-1}$. The container for the melt was a glassy carbon (GC) ampoule (type SU-2000), which played the role of auxiliary electrode simultaneously, potentials were measured versus the GC quasi-reference electrode. It is difficult to find the suitable reference electrode for chloride-oxyfluoride melts because of the corrosion action on glass or ceramics used as containers or diaphragms in construction of the traditional reference electrode. In this study that to avoid these difficulties a glassy carbon rod was used. The GC electrode monitors the redox potential of the melt, which remains constant, when composition of the melt is not changed. This potential was not defined thermodynamically, but due to GC quasi-reference electrode during experiments there was no contact between the melt and oxide materials. To obtain more reliable potentials values a $\mathrm{Ag} / \mathrm{NaCl}-\mathrm{KCl}-\mathrm{AgCl}$ (2 wt.\%) reference electrode was used. At the final stage of each set of experiments this reference electrode was immersed in the melt for a short time for determination of the potential peaks, the melt being no longer used after this immersion.

The electrolytic processes with accumulation of electrodeposited products were performed in galvanostatic mode. The cell, as a platinum crucible (30 $\mathrm{mm}$ diameter, $40 \mathrm{~mm}$ high), was placed inside a cylinder vessel made of heat-resistant steel with a brass water cooled lid. The vessel was filled with pure argon. Heating of the electrolyser was carried out in a shaft furnace with silicon carbide heaters; the temperature was maintained with the accuracy of $\pm 2{ }^{\circ} \mathrm{C}$. The anode (a tantalum square plate $3 \mathrm{~mm}$ thick) was placed at the bottom of the platinum crucible. Molybdenum rods ( $5 \mathrm{~mm}$ in diameter) were used as cathodes. Each portion of an electrolyte (about of $40 \mathrm{~g}$ ) served for a single cathodic deposition cycle only. To accumulate the product in each cycle a 5400 coulombs of electricity was passed. Cathodic products, after cooling to room temperature in argon atmosphere, were washed from the entrapped salt phase with $10 \%$-hydrochloric acid, then washed with distilled water and ethanol and finally dried in air at $40^{\circ} \mathrm{C}$.

A X-ray powder diffractometer DRON 2 supplied with computer data processing was used for the identification of the cathode products and electrolyte phase composition. A Stoe IPDS II diffractometer (Mo K $\alpha$ radiation) and the program JANA 2000 were used for the collection of experimental X-ray diffraction data and refinement of single crystal structure, respectively.

\section{Results and discussion}

Electrolytic processes with accumulation of cathodic products were for the most part carried out in electrolytes containing from 1.25 to $10 \mathrm{wt} \% \mathrm{~K}_{3} \mathrm{TaOF}_{6}$ dissolved in the $\mathrm{CsCl}$ melt. According to the XRD study, quenched electrolyte samples did not contain any other (new) phase in addition to the initial $\mathrm{CsCl}$ and $\mathrm{K}_{3} \mathrm{TaOF}_{6}$ in predetermined proportions. A few experiments were conducted using $\mathrm{Cs}_{3} \mathrm{TaOF}_{6}$ as a Ta-containing electrolyte component. The XRD results indicated that in this case the $x \mathrm{Cs}_{3} \mathrm{TaOF}_{6}-y \mathrm{CsCl}$ compound is formed after melting of the $\mathrm{CsCl}-\mathrm{Cs}_{3} \mathrm{TaOF}_{6}$ mixture.

\subsection{Phase composition of electrolysis products}

The change in phase composition of cathodic products obtained by electrolysis in the $\mathrm{CsCl}-\mathrm{K}_{3} \mathrm{TaOF}_{6}$ molten system as 
(A)

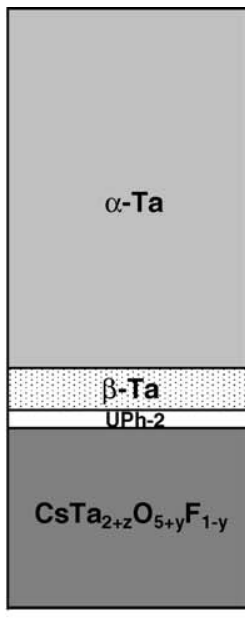

1

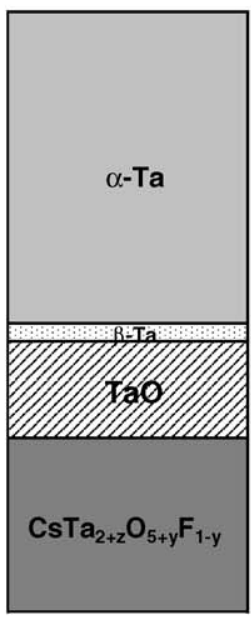

1

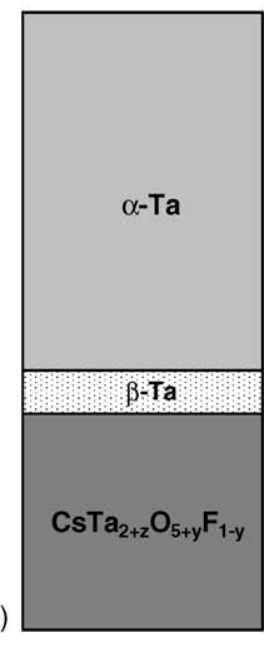

1

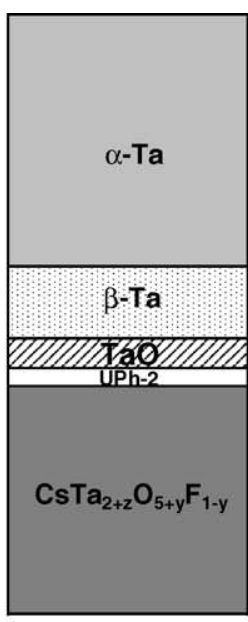

2

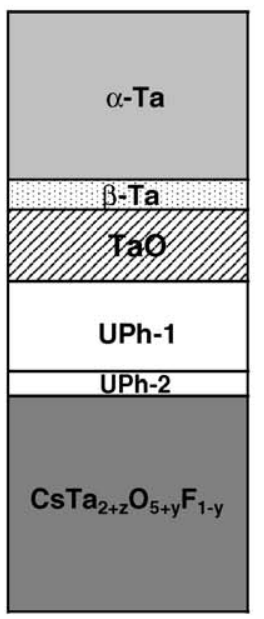

2

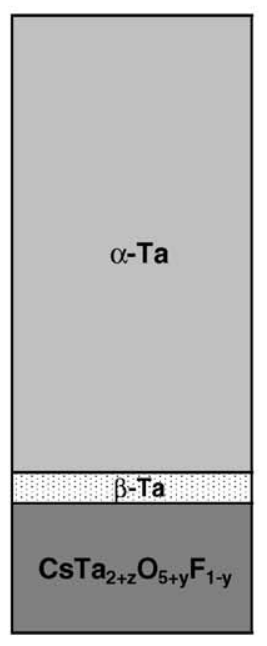

2

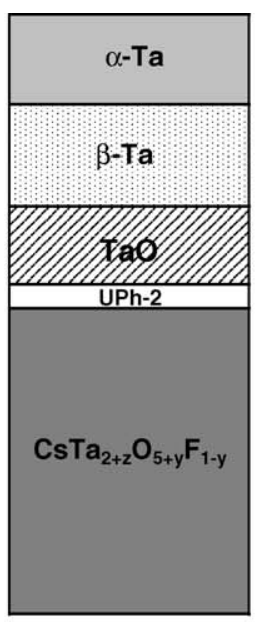

3

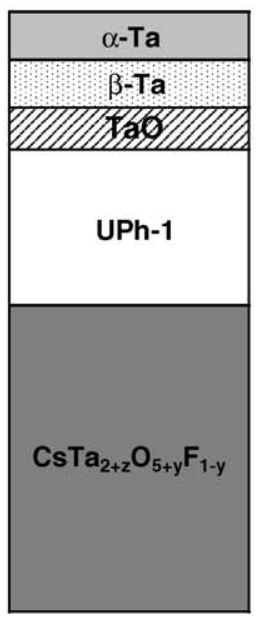

3

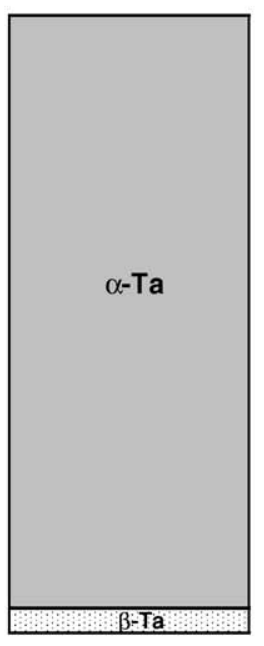

3

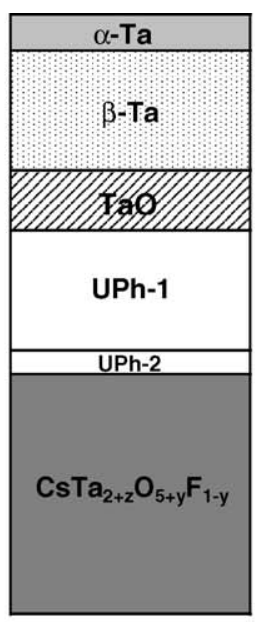

4

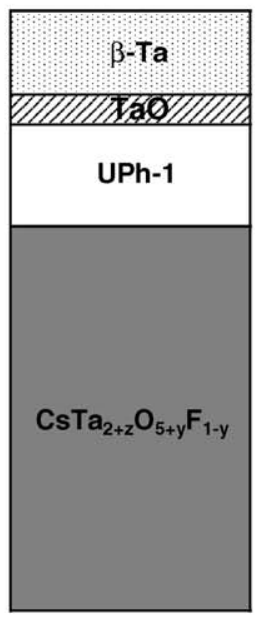

4

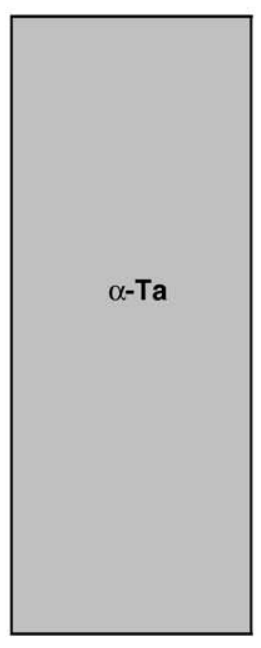

4
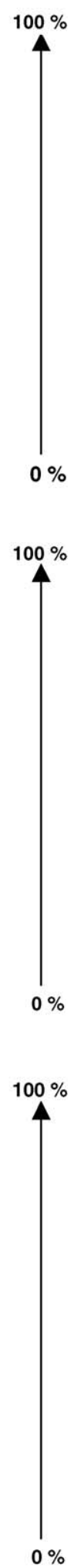

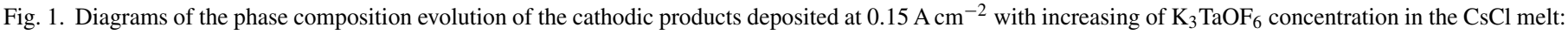
1.25 wt. $\%$ (1), 2.5 wt. $\%$ (2), 5.0 wt. $\%$ (3) and $10 \mathrm{wt} . \%$ (4) for temperatures: $650^{\circ} \mathrm{C}(\mathrm{A}), 750{ }^{\circ} \mathrm{C}(\mathrm{B})$ and $850{ }^{\circ} \mathrm{C}(\mathrm{C})$.

a function of $\mathrm{K}_{3} \mathrm{TaOF}_{6}$ concentration is shown in Fig. $1 \mathrm{~A}-\mathrm{C}$ at temperatures 650,750 and $850^{\circ} \mathrm{C}$, respectively. Fig. 2 indicates how the phase composition depends on cathodic current density for a $2.5 \mathrm{wt} . \% \mathrm{~K}_{3} \mathrm{TaOF}_{6}$ melt at $750{ }^{\circ} \mathrm{C}$.
As can be seen from Figs. 1 and 2, several phases generally crystallized at the cathode simultaneously. The set of phases in cathodic deposits depends on all electrolysis parameters and may include the following phases: 


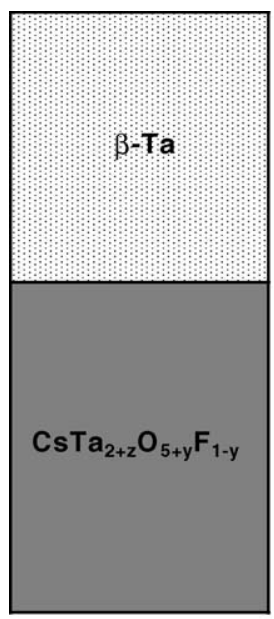

1

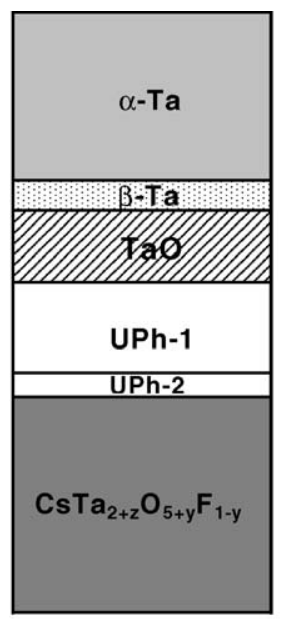

2

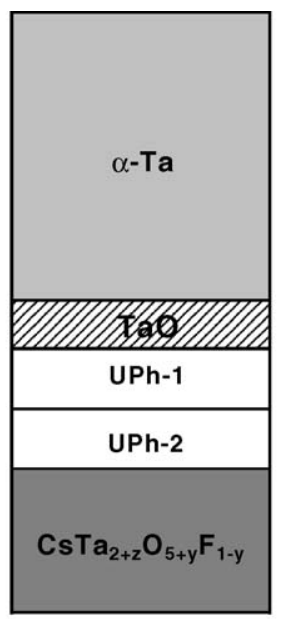

3

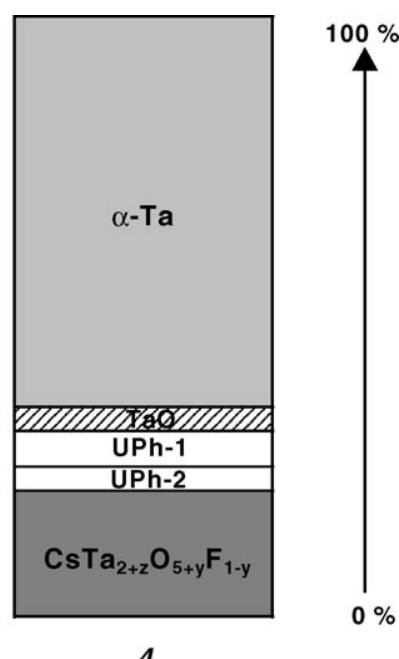

Fig. 2. Diagrams of the phase composition evolution of the cathodic products deposited at $750{ }^{\circ} \mathrm{C}$ in the $\mathrm{CsCl}-2.5$ wt. $\% \mathrm{~K}_{3} \mathrm{TaOF}_{6}$ melt with increasing of the cathodic current density: $0.05 \mathrm{~A} \mathrm{~cm}^{-2}$ (1), $0.15 \mathrm{~A} \mathrm{~cm}^{-2}$ (2), $0.25 \mathrm{~A} \mathrm{~cm}^{-2}$ (3) and $0.5 \mathrm{~A} \mathrm{~cm}^{-2}$ (4).

- $\alpha$-Ta - the cubic tantalum modification with body-centered crystal lattice [9], which is a unique tantalum modification produced by universally accepted metallurgical techniques.

- $\beta-\mathrm{Ta}$ - the tetragonal tantalum modification whose structure belongs to the Frank-Kasper structures of $\sigma$-type [10], which are typical for binary intermetallic compounds such as $\mathrm{Fe}-\mathrm{Cr}$.

Tantalum of this modification could be apparently prepared only in the presence on an electric field: by direct current magnetron sputtering [11] or using the electrodeposition from molten salts $[12,13]$. The structure of $\beta$-Ta was described in detail in our publication [14]:

- $\mathrm{TaO}$ - the lower tantalum oxide with tetragonal crystal lattice [15].

Two different types of octahedral crystals with the similar general composition $\mathrm{CsTa}_{2+z}{ }^{n+} \mathrm{O}_{5+y} \mathrm{~F}_{1-y}$. Here the oxidation state of Ta $\left(n^{+}\right)$depends on both a number of intercalated tantalum ions $(z)$ and a number of fluorine ions replaced by oxygen ions $(y)$ in the structure through the electroreducing process. From the charge balance, $n=(10+y) /(2+z) \leq 5$; hence $y \leq 5 z$. These crystals have been deposited at the cathode during most of electrolysis cycles. The lamellar crystals of the first type (I) are transparent, colorless and dielectric similar to the ones described in [16]. The crystals of another type (II) are black and metal-like, pointing to an oxidation state of the Ta ion lower than 5. The relative amount of the crystals I in reference to the crystals II in the cathodic deposits was not more than $1 / 10$. Peculiarities of the compounds I and II structures will be discussed below in special paragraph:

- UPh-1 - a conductive phase, which is present always only together with the phase-CsTa $2+z{ }^{5-x} \mathrm{O}_{5+y} \mathrm{~F}_{1-y}$, and as the latter has a metallic appearance. Its chemical composition is not yet determined because of difficulties to isolate it from other metal-like phases presenting in deposits.

- UPh-2 - beige colored scales of various tinge, which also were always deposited together with the phases I and II. According to XRD data, the phase $\mathrm{UPh}-2$ is a full structural analogue of the hexagonal calcite $\mathrm{CaCO}_{3}$. Its chemical composition is under study.

SEM images of some characteristic phases obtained by electrolysis in $\mathrm{CsCl}-\mathrm{K}_{3} \mathrm{TaOF}_{6}$ melt are shown in Fig. 3. X-ray patterns of one of the most multiphase deposits, and two individual phases: $\mathrm{CsTa}_{2+z}{ }^{n+} \mathrm{O}_{5+y} \mathrm{~F}_{1-y}$ and $\mathrm{UPh}-2$ are displayed in Fig. 4.

As can be seen from the diagrams of Fig. 1, compounds $\mathrm{CsTa}_{2+z}{ }^{n+} \mathrm{O}_{5+y} \mathrm{~F}_{1-y}$ abound in all electrolysis products obtained at temperatures 650 and $750{ }^{\circ} \mathrm{C}$ without regard to parameters of the electrolytic process. At these temperatures the total relative share of all nonmetallic phases has tendency to increase as the $\mathrm{K}_{3} \mathrm{TaOF}_{6}$ concentration increases in the melt with the most significant growth of $\mathrm{CsTa}_{2+z}{ }^{n+} \mathrm{O}_{5+y} \mathrm{~F}_{1-y}$ phase amount. As regards to the composition of metallic fraction $(\alpha-\mathrm{Ta}+\beta-\mathrm{Ta})$ the proportion of $\beta$-Ta phase monotonically increases in it with increasing of the $\mathrm{K}_{3} \mathrm{TaOF}_{6}$ concentration.

An opposite regularity takes place at the highest of tested temperatures $-850^{\circ} \mathrm{C}$. In this case $\mathrm{CsTa}_{2+z}{ }^{n+} \mathrm{O}_{5+y} \mathrm{~F}_{1-y}$ phase was presented in cathodic deposits only when the $\mathrm{K}_{3} \mathrm{TaOF}_{6}$ concentration did not exceed $5 \mathrm{wt} . \%$, and no other nonmetallic phases formed in cathodic products at any $\mathrm{K}_{3} \mathrm{TaOF}_{6}$ concentrations. As to metallic tantalum, it mainly crystallized in the cubic modification. In any event, the metastable phase of $\beta-\mathrm{Ta}$, even deposited at the cathode, should quickly transform to the thermodynamically stable $\alpha$-Ta phase at such high temperature [13].

Fig. 2 shows that cathodic current density has the certain effect on the relationship between amounts of metallic and nonmetallic phases in electrolysis products obtained at the temperature $750{ }^{\circ} \mathrm{C}$ and concentration $2.5 \mathrm{wt} . \% \mathrm{~K}_{3} \mathrm{TaOF}_{6}$ in the melt. At the same time the $\beta$-Ta phase may be only deposited at relatively low current densities, no more than $0.15 \mathrm{~A} \mathrm{~cm}^{-2}$ giving way to another tantalum modification and the proportion 

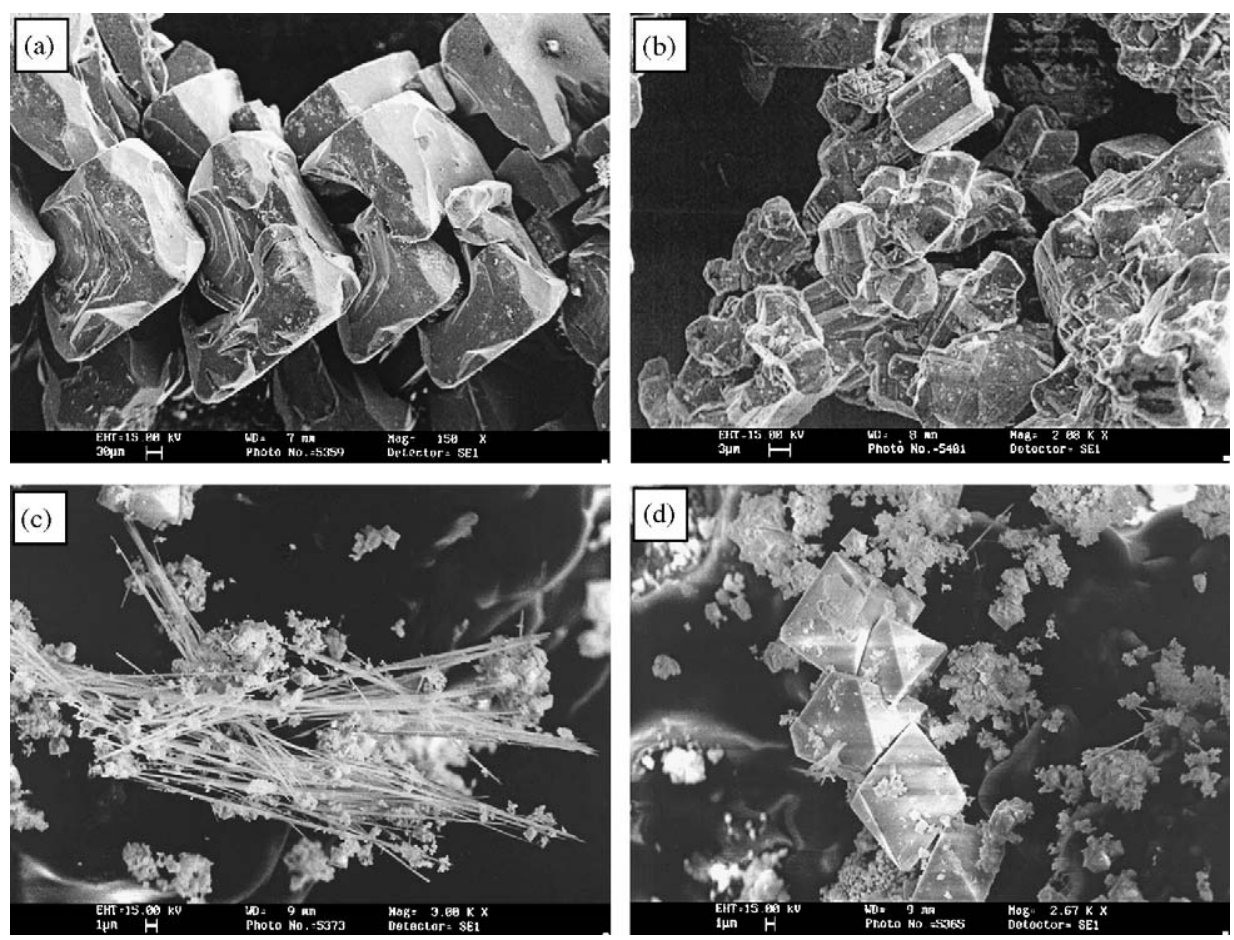

Fig. 3. SEM images of some characteristic phases obtained by electrolysis in the $\mathrm{CsCl}-\mathrm{K}_{3} \mathrm{TaOF}_{6}$ melt: (a) $\alpha$-Ta electrolytic crystal extracted from the cathodic product obtained at $750{ }^{\circ} \mathrm{C}$ and $0.15 \mathrm{~A} \mathrm{~cm}^{-2}$ in the CsCl-1.25 wt. $\% \mathrm{~K}_{3} \mathrm{TaOF}_{6}$ melt, (b) typical crystalline aggregations of the $\beta$-Ta phase in the deposit obtained at $750{ }^{\circ} \mathrm{C}$ and $0.15 \mathrm{~A} \mathrm{~cm}^{-2}$ in the $\mathrm{CsCl}-2.5 \mathrm{wt} . \% \mathrm{~K}_{3} \mathrm{TaOF}_{6}$ melt, (c) and (d) different segments of the cathodic product obtained at $650{ }^{\circ} \mathrm{C}$ and $0.15 \mathrm{~A} \mathrm{~cm}{ }^{-2}$ in the CsCl-5 wt. $\% \mathrm{~K}_{3} \mathrm{TaOF}_{6}$ melt. Thin needles of $\mathrm{TaO}$ (c) and octahedral crystals of the $\mathrm{CsTa}_{2+z}{ }^{5-x} \mathrm{O}_{5+y} \mathrm{~F}_{1-y}$ phase (d) present the main part of the product.

of $\mathrm{CsTa}_{2+z}{ }^{n+} \mathrm{O}_{5+y} \mathrm{~F}_{1-y}$ phase decreases as the current density increases.

From the data presented in Figs. 1 and 2 it may be concluded that high temperature and low current density will conduce to reducing of phase number in cathodic deposits, since electrochemical process conditions in these cases should be most close to equilibrium.

Unfortunately now we are not able to explain in more detail the changes of phase composition as a function of parameters (Figs. 1 and 2). For strict correlation of cathodic product composition and electrodeposition parameters, the results of potentiostatic electrolysis will be provided, which is the task of current studies.

The above results were obtained when Ta-ions were introduced in an electrolyte with $\mathrm{K}_{3} \mathrm{TaOF}_{6}$. Therefore, potassium cations as well as caesium ones could be present in the second coordination sphere of tantalum complexes in the melt. In this connection it was interesting to estimate the phase composition of cathodic products obtained when only caesium species are presents in molten electrolyte.

Table 1 shows that replacing of $\mathrm{K}_{3} \mathrm{TaOF}_{6}$ by $\mathrm{Cs}_{3} \mathrm{TaOF}_{6}$ has not a very great effect on the composition of cathodic products. The result obtained was rather unexpected, considering that such a substitution led to a considerable change in electrolyte phase composition as was noted above.

\subsection{Structural investigation of $\mathrm{CsTa}_{2+z}{ }^{n+} \mathrm{O}_{5+y} F_{1-y}(n \leq 5)$ phases}

Only $\mathrm{CsTa}_{2}{ }^{n+} \mathrm{O}_{5} \mathrm{~F}$ has been described before with the highest oxidation state of $\mathrm{Ta}$ [16]. The published structural data only give the cationic positions. Our single crystal investigations of (I) and (II) confirmed the main cationic positions of Cs and Ta ions obtained by Babel et al. [16] and indicated clearly that both types

Table 1

Phase compositions of cathodic products obtained at temperature $750{ }^{\circ} \mathrm{C}$ and $d_{\mathrm{c}}=0.15 \mathrm{~A} \mathrm{~cm}^{-2}$ in $\mathrm{CsCl}-\mathrm{K}_{3} \mathrm{TaOF}_{6}$ and $\mathrm{CsCl}-\mathrm{Cs}_{3} \mathrm{TaOF}_{6} \mathrm{melts}$

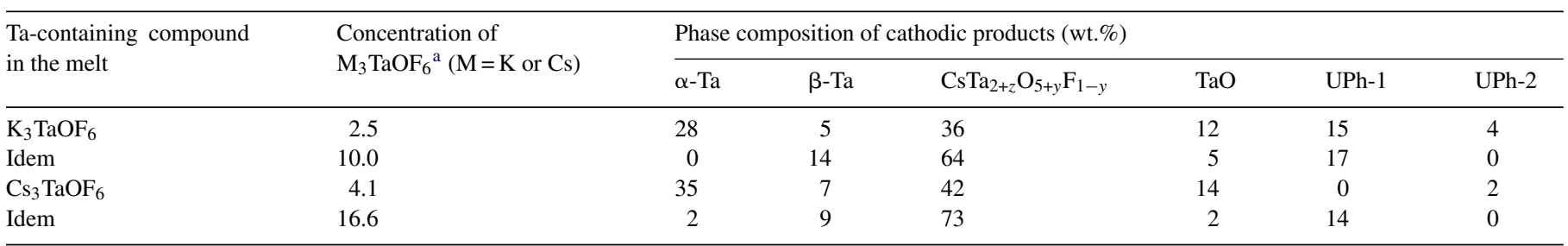

\footnotetext{
a The concentrations of $\mathrm{K}_{3} \mathrm{TaOF}_{6}$ and $\mathrm{Cs}_{3} \mathrm{TaOF}_{6}$ (wt.\%) are equivalent regarding the amounts of $\mathrm{Ta}^{5+}$ in a melt.
} 


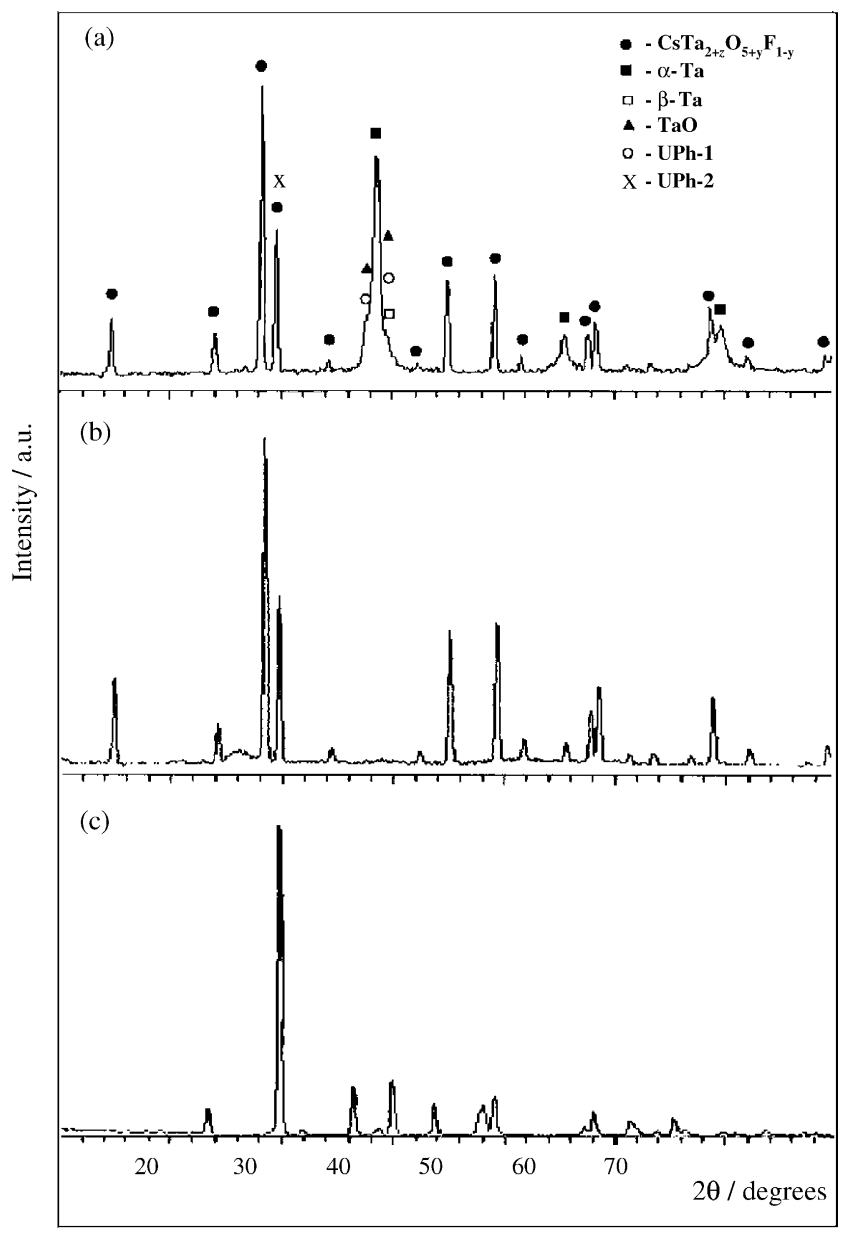

Fig. 4. XRD patterns of the deposit presented at diagram B2 of Fig. 1 (a) and of two separated individual phases: $\mathrm{CsTa}_{2+z} \mathrm{O}_{5+y} \mathrm{~F}_{1-y}$ (b) and UPh-2 (c).

of crystals are isostructural to $\mathrm{RbTa}_{2} \mathrm{O}_{5} \mathrm{~F}$ [17] with the same space group $F d 3 m$, the same unit cell parameter, $a=10.499(1) \AA$, and the same positions of the basic ions (Table 2). Both structures were refined with high accuracy ( $R$-factors equal to 0.0223 and 0.0172 for type I and II crystals, respectively).

The main building element of the structure type (Fig. 5) can be described as a pyrochlor framework with the chemical composition $\mathrm{TaX}_{3}$. The framework consists of $\left[\mathrm{TaX}_{6}\right]$-octahedrons shar-

Table 2

Structural characteristics of $\mathrm{CsTa}_{2+z}{ }^{n+} \mathrm{O}_{5+y} \mathrm{~F}_{1-y}(n \leq 5)$

\begin{tabular}{llll}
\hline Atom & $\begin{array}{l}\text { Wyckoff } \\
\text { position }\end{array}$ & $\begin{array}{l}\text { Coordinates in the } \\
\text { unit cell }(x y z)\end{array}$ & $\begin{array}{l}\text { Population } \\
\text { coefficient, } p\end{array}$ \\
\hline $\mathrm{Ta}$ & $16 c$ & $(000)$ & 1 \\
$\mathrm{Cs}$ & $8 b$ & $(1 / 81 / 85 / 8)$ & 1 \\
$\mathrm{X}=(\mathrm{O}, \mathrm{F})^{\mathrm{a}}$ & $48 f$ & $\begin{array}{l}(7 / 8 y 7 / 8) ; \mathrm{I}: \\
y=0.0626(5) ; \mathrm{II}:\end{array}$ & 1 \\
& & $\begin{array}{l}y=0.0630(3) \\
(7 / 87 / 87 / 8)\end{array}$ & \\
$\mathrm{Ta}_{\text {int }}$ & $8 a$ & & I: $0.018(4) ; \mathrm{II}:$ \\
& & & $0.006(1)$
\end{tabular}

The variable parameters are given for two different crystals: I (transparent and colorless); II (black-metallic).

a Both $\mathrm{O}^{2-}$ and $\mathrm{F}^{-}$anions occupy statistically the common structural position $\mathrm{X}=(\mathrm{O}, \mathrm{F})$.

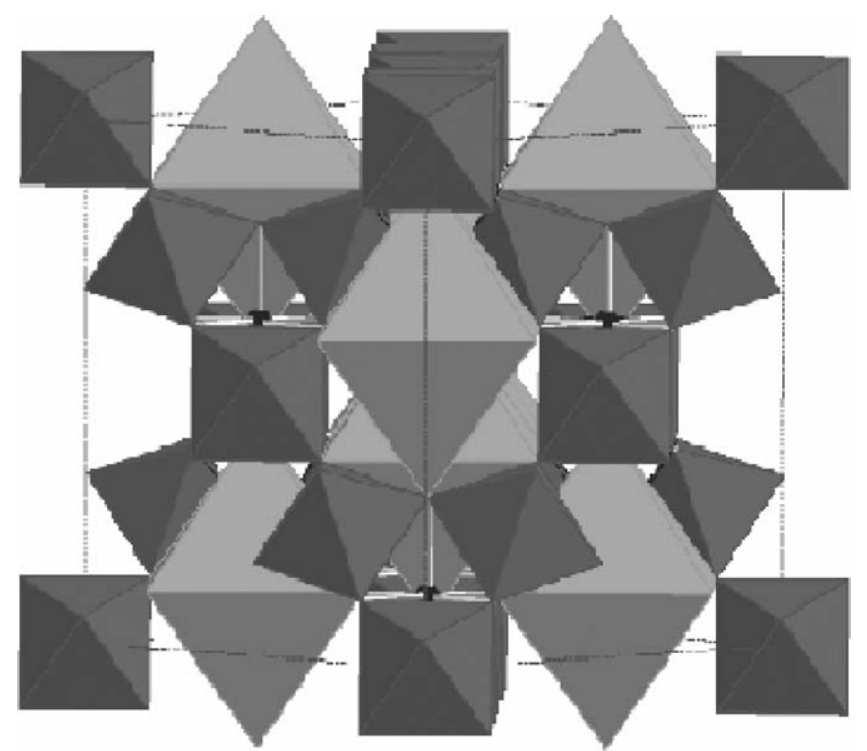

Fig. 5. Crystal structure of $\mathrm{CsTa}_{2+z}{ }^{n+} \mathrm{X}_{6}(n<5)$, where anion $\mathrm{X}=(\mathrm{O}, \mathrm{F})$. The pyrochlor-like framework consists of $\left[\mathrm{TaX}_{6}\right]$-octahedra (dark gray color) sharing all they vertices. The $\mathrm{Cs}$ atoms are locates in large light gray color of the framework. Positions of intercalated Ta atoms are shown by the black small circles connected with nearest anions (vertices of polyhedron). The cubic unit cell is indicated with dotted lines.

ing all their vertices. The chemical composition of the framework and the connection between octahedrons are analogous to Ta-bronzes [18]. The Cs ions are located in large octahedron formed by the anions (Cs-X distance is equal to 3.276(6) and 3.279(5) $\AA$ in I and II, respectively). Both types of crystals are characterized by intercalations defects: the $8 a$ position is slightly occupied with $\mathrm{Ta}_{\text {int }}$ ions (Table 2). These additional atoms are located in the center of $\left[\mathrm{Ta}_{\mathrm{int}} \mathrm{X}_{6}\right]$-octahedron, similar to the $\left[\mathrm{TaX}_{6}\right]$-octahedron of the framework. The difference between crystals I and II is revealed in the concentration of the defects: the number of defects per unit cell in I is three times larger than in II (the $p$ coefficient in Table 2).

The $\mathrm{Ta}_{\text {int }}-\mathrm{O}$ and $\mathrm{Ta}-\mathrm{O}$ distances are equal to each other for I (1.970(5) and 1.969(2) $\AA$, respectively), while for II, the $\mathrm{Ta}_{\text {int }}-\mathrm{O}$ distance is larger than the Ta-O distance (1.974(5) and $1.970(2) \AA$, respectively). This difference indicates that the Taint ions have the oxidation state $n=5$ in I and $n<5^{+}$in II. The increase of the $\mathrm{Ta}_{\text {int }}-\mathrm{O}$ distance is associated with increasing $\mathrm{Ta}_{\text {inc }}$ ionic radius in II, due to reduction of their oxidation state. The overall electroneutrality is most likely controlled by the amount of F-ions in the mixed anion position $\mathrm{X}$. The F/O ratio is larger in II than in I, owing to the higher defect concentration and higher oxidation state of all Ta ions in I. Taking into account the structural data and the oxidation state of the Ta ions in I which is equal 5 , the formula of $\mathrm{I}$ can be more precisely expressed as $\mathrm{CsTa}_{2.01}{ }^{5+} \mathrm{O}_{5.05} \mathrm{~F}_{0.95}$. The partial reduction of Ta ions does not allow to give a single-valued formula for crystal II. In contrast to the compounds under discussion, it is interesting to mention that the anionic composition of the $\left[\mathrm{TaX}_{3}\right]$ framework, that is $\mathrm{F} / \mathrm{O}$ ratio, is constant regardless of the tantalum oxidation state in Ta-bronzes $[18,19]$. 


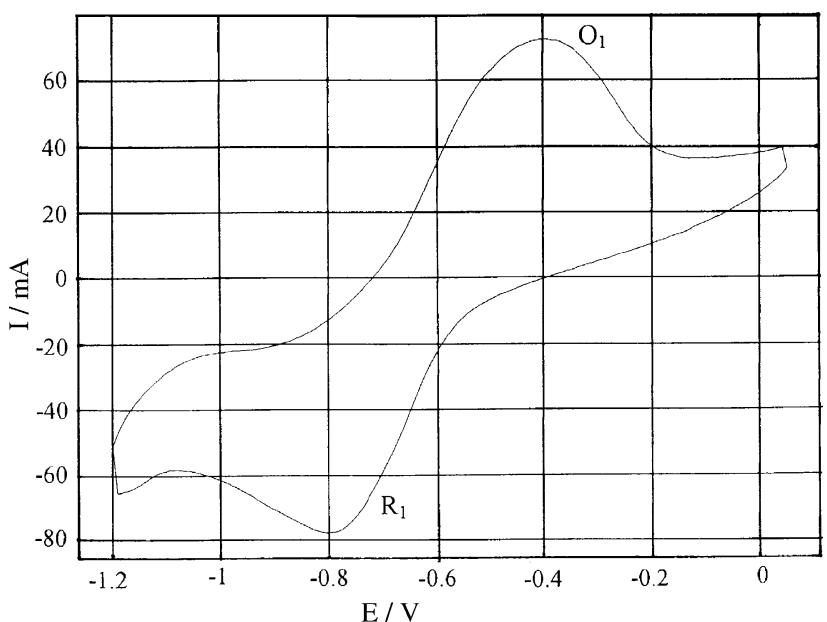

Fig. 6. Cyclic voltammograms at silver electrode in $\mathrm{CsCl}-\mathrm{K}_{3} \mathrm{TaOF}_{6}$ melt. Area: $0.447 \mathrm{~cm}^{2}$. Sweep rate: $0.2 \mathrm{~V} \mathrm{~s}^{-1}$. Temperature: $700^{\circ} \mathrm{C}$. Concentration of $\mathrm{K}_{3} \mathrm{TaOF}_{6}: 1.01 \times 10^{-4} \mathrm{~mol} \mathrm{~cm}^{-3}$. Quasi-reference electrode: glassy carbon.

\subsection{Study of electrochemical reduction of tantalum oxyfluoride complexes in $\mathrm{CsCl}$}

Polarization curves for tantalum oxyfluoride complexes in $\mathrm{CsCl}$ melt were obtained by cyclic voltammetry method. Fig. 6 shows that a discharge peak $\left(R_{1}\right)$ and a newly developing peak at around $-1.1 \mathrm{~V}$ in the potentials region up to $-1.2 \mathrm{~V}$ at $700^{\circ} \mathrm{C}$ (relative to the GC quasi-reference electrode) are observed on cyclic voltammograms in $\mathrm{CsCl}-\mathrm{K}_{3} \mathrm{TaOF}_{6}$ melt. The nature of the latter peak will be discussed below. According to [20], this peak corresponds to the discharge of tantalum monooxyfluoride complexes to tantalum metal or its monoxide $\mathrm{TaO}$, evidently by the reactions

$$
\begin{aligned}
& \mathrm{TaOF}_{6}{ }^{3-}+5 \mathrm{e}^{-} \rightarrow \mathrm{Ta}+\mathrm{O}^{2-}+6 \mathrm{~F}^{-} \\
& \mathrm{TaOF}_{6}{ }^{3-}+3 \mathrm{e}^{-} \rightarrow \mathrm{TaO}+6 \mathrm{~F}^{-}
\end{aligned}
$$

In the presence of $\mathrm{Cs}^{+}$outer-sphere cations in the melt, the discharge of $\mathrm{TaOF}_{6}{ }^{3-}$ anions with the formation of low-valence pyrochlor type phase also seems to be occurring at the peak $R_{1}$ potential. A plausible reaction for the case of $\mathrm{Ta}(\mathrm{V})$ to $\mathrm{Ta}(\mathrm{IV})$ electrochemical reduction should be as follows:

$$
\begin{aligned}
& 10 \mathrm{TaOF}_{6}{ }^{3-}+2 \mathrm{Cs}^{+}+5 \mathrm{e}^{-} \\
& \quad \rightarrow 2 \mathrm{CsTa}_{2.5} \mathrm{O}_{5} \mathrm{~F}+5 \mathrm{TaF}_{7}{ }^{2-}+23 \mathrm{~F}^{-}
\end{aligned}
$$

Rather large width of the peak $R_{1}$ on the curve recorded at $700^{\circ} \mathrm{C}$ (Fig. 6) is probably just a consequence of simultaneous passage of all above-listed reactions at close potentials.

The effects of $\mathrm{K}_{3} \mathrm{TaOF}_{6}$ concentration in the melt and polarization scan rate $(v)$ on the peak current $\left(I_{\mathrm{p}}^{\mathrm{c}}\right)$ and the peak potential $\left(E_{\mathrm{p}}^{\mathrm{c}}\right)$ of the $\mathrm{TaOF}_{6}{ }^{3-}$ complexes electroreduction were studied at temperature $700^{\circ} \mathrm{C}$. The following peculiarities were established: $E_{\mathrm{p}}^{\mathrm{c}}$ shifted to the negative direction with increasing of $v$, but the potential shift is not very significant up to $0.3 \mathrm{~V} \mathrm{~s}^{-1}$. The $I_{\mathrm{p}}^{\mathrm{c}} / v^{1 / 2}$ ratio decreases as $v$ increases up to $0.3 \mathrm{~V} \mathrm{~s}^{-1}$. $E_{\mathrm{p}}^{\mathrm{c}}$ is essentially independent of $\mathrm{K}_{3} \mathrm{TaOF}_{6}$ in the concentration range from $4 \times 10^{-5}$ up to $3.5 \times 10^{-4} \mathrm{~mol} \mathrm{~cm}^{-3}$. Taking into account

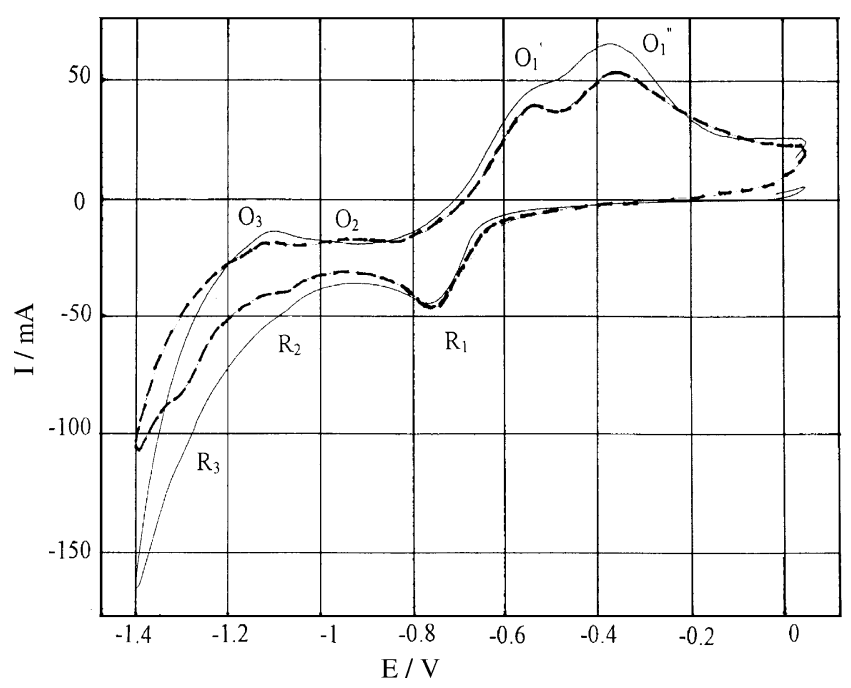

Fig. 7. Cyclic voltammetric curves at silver electrode in $\mathrm{CsCl}-\mathrm{K}_{3} \mathrm{TaOF}_{6}-$ $\mathrm{K}_{3} \mathrm{TaO}_{2} \mathrm{~F}_{4}$ melt. Area: $0.353 \mathrm{~cm}^{2}$. Sweep rate: $0.1 \mathrm{~V} \mathrm{~s}^{-1}$. Temperature: $810^{\circ} \mathrm{C}$. Concentration of $\mathrm{K}_{3} \mathrm{TaOF}_{6}: 9.62 \times 10^{-5} \mathrm{~mol} \mathrm{~cm}^{-3}$. Concentration of $\mathrm{K}_{3} \mathrm{TaO}_{2} \mathrm{~F}_{4}: 8.41 \times 10^{-5} \mathrm{~mol} \mathrm{~cm}^{-3}$. Quasi-reference electrode: glassy carbon. Dashed line: before addition of $\mathrm{K}_{3} \mathrm{TaO}_{2} \mathrm{~F}_{4}$. Solid line: after addition of $\mathrm{K}_{3} \mathrm{TaO}_{2} \mathrm{~F}_{4}$.

these peculiarities, it may be concluded that most likely the electroreduction process proceeds quasi-reversibly with a preceding chemical reaction. Probably, such a chemical reaction is a partial dissociation of the $\mathrm{TaOF}_{6}{ }^{3-}$ complexes in the diffusion layer, which is associated with the differences in bonds lengths between tantalum as central atom and various ligands. Analytical solution of such a kind of process is unknown, so no calculation of the number electrons and others kinetic parameters is available.

Fig. 7 shows cyclic voltammograms of the $\mathrm{CsCl}-\mathrm{K}_{3} \mathrm{TaOF}_{6}$ melt at temperature $810^{\circ} \mathrm{C}$ obtained at more extended potentials range. Three cathodic waves $\left(R_{1}, R_{2}\right.$ and $\left.R_{3}\right)$ are detected on these voltammograms and three corresponding peaks of electrooxidation. Presence of $R_{2}$ wave in a melt containing initially only monooxyfluoride complexes can be explained by the generation of free oxygen anions in the near-electrode layer due to the cathodic process (1) and by occurrence of the exchange reaction

$\mathrm{TaOF}_{6}{ }^{3-}+\mathrm{O}^{2-} \leftrightarrow \mathrm{TaO}_{2} \mathrm{~F}_{4}{ }^{3-}+2 \mathrm{~F}^{-}$

The tantalum dioxyfluoride complexes that are formed by reaction (4) are discharge at more negative potential than monooxyfluoride ones (Fig. 7). To confirm our supposition regarding the nature of $R_{2}$ wave, $1.0 \mathrm{~g}$ of $\mathrm{K}_{3} \mathrm{TaO}_{2} \mathrm{~F}_{4}$ synthesized beforehand was added to the melt containing $60 \mathrm{~g}$ of $\mathrm{CsCl}$ and $3.3 \mathrm{~g}$ of $\mathrm{K}_{3} \mathrm{TaOF}_{6}$. Some increase of $R_{2}$ wave height was observed after addition (Fig. 7). The wave $R_{2}$ after addition of $\mathrm{K}_{3} \mathrm{TaO}_{2} \mathrm{~F}_{4}$ had not clear peak, but there was a bend observed on the voltammogram in the region of potentials corresponding to wave $R_{2}$. This fact corroborates that $R_{2}$ is just the wave related to the discharge of the $\mathrm{TaO}_{2} \mathrm{~F}_{4}{ }^{3-}$ complexes. But increase of $R_{2}$ wave height was not proportional to the quantity of added $\mathrm{K}_{3} \mathrm{TaO}_{2} \mathrm{~F}_{4}$. That can be explained by the fairly low solubility of $\mathrm{K}_{3} \mathrm{TaO}_{2} \mathrm{~F}_{4}$ in the $\mathrm{CsCl}$ melt. Indeed, about $0.4 \mathrm{~g}$ of a bottom 
deposit was observed in the reaction vessel after the experiment. According to chemical analysis and XRD data, this deposit represented the monophase of the $\mathrm{CsTa}_{2+z}{ }^{5+} \mathrm{O}_{5+y} \mathrm{~F}_{1-y}$ compound, which can be formed possibly by reaction of $\mathrm{CsCl}$ with the rest of $\mathrm{K}_{3} \mathrm{TaO}_{2} \mathrm{~F}_{4}$ undissolved in the melt

$$
\begin{aligned}
& 3 \mathrm{~K}_{3} \mathrm{TaO}_{2} \mathrm{~F}_{4}+\mathrm{CsCl} \\
& \quad=\mathrm{CsTa}_{2} \mathrm{O}_{5} \mathrm{~F} \downarrow+\mathrm{K}_{3} \mathrm{TaOF}_{6}+5 \mathrm{KF}+\mathrm{KCl}
\end{aligned}
$$

Rather low solubility of $\mathrm{K}_{3} \mathrm{TaO}_{2} \mathrm{~F}_{4}$ in molten $\mathrm{CsCl}$ is also manifested in moderate distinction in phase composition of cathodic deposits obtained in $\mathrm{CsCl}-\mathrm{K}_{3} \mathrm{TaOF}_{6}$ melts with and without addition of potassium dioxyfluorotantalate. Thus, with addition of $1.5 \mathrm{wt} . \%$ of $\mathrm{K}_{3} \mathrm{TaO}_{2} \mathrm{~F}_{4}$ to the melt containing $2.5 \mathrm{wt} . \%$ of $\mathrm{K}_{3} \mathrm{TaOF}_{6}$ the proportion of Ta metal in the deposits produced at temperature $750{ }^{\circ} \mathrm{C}$ and $d_{\mathrm{c}}=0.05 \mathrm{~A} \mathrm{~cm}^{-2}$ decreased from $45 \%$ (Fig. 2, diagram 1) to approximately $40 \%$ and the proportion of $\mathrm{CsTa}_{2+z}{ }^{5-x} \mathrm{O}_{5+y} \mathrm{~F}_{1-y}$ increased, respectively from 55 to $60 \%$.

As to peak $R_{3}$ around $-1.3 \mathrm{~V}$ in Fig. 7 , it can be attributed to an alkali metal cations discharge on the surface of deposited products at the potentials of $R_{1}$ and $R_{2}$ waves. A depolarization observed at the curves of Fig. 7 is most likely caused by a reduction reaction of these products by an alkali metal. This supposition correlates well with the results of our investigation of the effect of cathodic current density influence on the electrolysis products phase composition. Thus, exceeding a limiting diffusion current density of monooxofluorotantalate complexes discharge (according to the steady-state voltammetry data it takes place at about $0.25 \mathrm{~A} \mathrm{~cm}^{-2}$ at $2.5 \mathrm{wt} . \% \mathrm{~K}_{3} \mathrm{TaOF}_{6}$ and temperature $750^{\circ} \mathrm{C}$ ) entailed an increase of the $\alpha$-Ta phase proportion in cathodic deposits (Fig. 2). In this case, the cubic tantalum modification appears to be formed not only by direct electrochemical crystallization, but also by a metallothermic reduction of $\mathrm{TaO}$ or other tantalum compounds with potassium or caesium as reducing agents.

The diagrams of Figs. 1 and 2 favour the view that the electroreduction of $\mathrm{TaOF}_{6}{ }^{3-}$ complexes can occur by reactions (1)-(3) at temperatures 650 and $750{ }^{\circ} \mathrm{C}$. But at $850{ }^{\circ} \mathrm{C}$ the presence of $\mathrm{TaO}$ has not been observed in cathodic deposits. The latter suggests that in this case either cathodic process does not goes by the reaction (2) or $\mathrm{TaO}$ formed by this reaction then decomposes into $\mathrm{Ta}$ and $\mathrm{O}_{2}$, since $\mathrm{TaO}$ is rather unstable composition and the Gibbs energy of its decomposition is very negative $[20,21]$. The kinetics of $\mathrm{TaO}$ the decomposition reaction is more rapid at the temperature $850{ }^{\circ} \mathrm{C}$ than for $750{ }^{\circ} \mathrm{C}$.

This suggestion is in accordance with voltammetric curves obtained at temperature 700 and $850{ }^{\circ} \mathrm{C}$ (Fig. 8). Actually, at

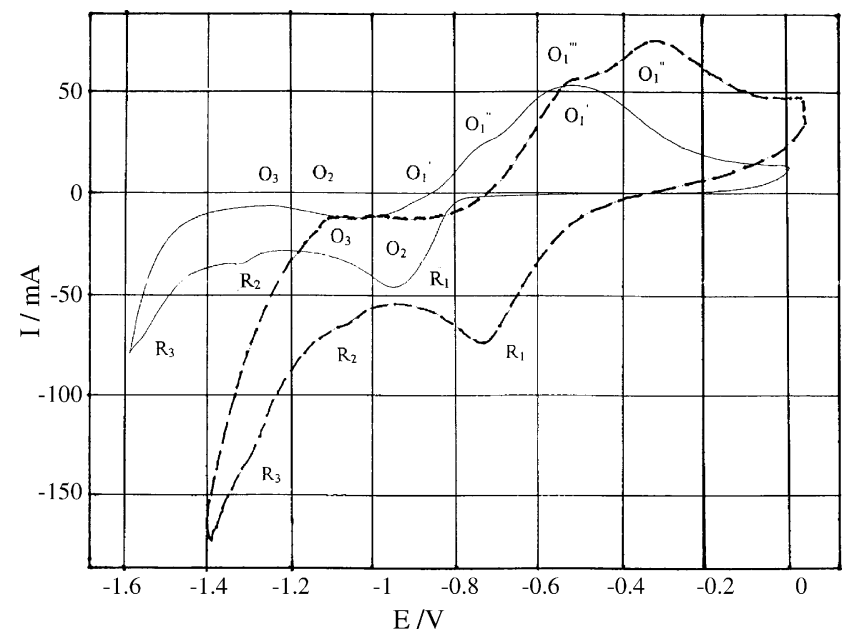

Fig. 8. Cyclic voltammograms at silver electrode in $\mathrm{CsCl}-\mathrm{K}_{3} \mathrm{TaOF}_{6}$ melt Area: $0.447 \mathrm{~cm}^{2}$. Sweep rate: $0.1 \mathrm{~V} \mathrm{~s}^{-1}$. Concentration of $\mathrm{K}_{3} \mathrm{TaOF}_{6}$ : $1.01 \times 10^{-4} \mathrm{~mol} \mathrm{~cm}^{-3}$. Reference electrode: $\mathrm{Ag} / \mathrm{NaCl}-\mathrm{KCl}-\mathrm{AgCl}$ (2 wt.\%). Solid line: temperature $700^{\circ} \mathrm{C}$. Dashed line: temperature $850^{\circ} \mathrm{C}$.

temperature $700{ }^{\circ} \mathrm{C}$ to wide peak $R_{1}$ corresponds three electrooxidation peaks $\left.\left(\mathrm{O}_{1}^{\prime}, \mathrm{O}_{1}^{\prime \prime}, \mathrm{O}_{1}^{\prime \prime \prime}\right)\right)$ of products, which are formed during cathodic cycle (1)-(3). At the same time at temperature $850^{\circ} \mathrm{C}$ to wave $R_{1}$ two corresponding electrooxidation peaks $\left(\mathrm{O}_{1}^{\prime}, \mathrm{O}_{1}^{\prime \prime}\right)$ were observed in anodic one-half cycle (Fig. 8). These two waves were registered on the voltammograms at temperature $810^{\circ} \mathrm{C}$ also (Fig. 7).

The electrochemical process (1), which is accompanied by the generation of free, not bonded in complexes oxygen anions in near-electrode layer may result in local chemical reactions in this layer with formation of dielectric $\mathrm{Ta}^{5+}$-compounds, for example

$$
\begin{aligned}
& 2 \mathrm{TaOF}_{6}{ }^{3-}+3 \mathrm{O}^{2-}+\mathrm{Cs}^{+} \rightarrow \mathrm{CsTa}_{2} \mathrm{O}_{5} \mathrm{~F} \downarrow+11 \mathrm{~F}^{-} \\
& 2 \mathrm{TaO}_{2} \mathrm{~F}_{4}{ }^{3-}+\mathrm{O}^{2-}+\mathrm{Cs}^{+} \rightarrow \mathrm{CsTa}_{2} \mathrm{O}_{5} \mathrm{~F} \downarrow+7 \mathrm{~F}^{-}
\end{aligned}
$$

Other possible reason for the nucleation of $\mathrm{Ta}^{5+}$-compounds phases during electrolysis may be local fluctuations of the melt composition in near-cathode layer associated with selective removal of tantalum species from the melt by their cathodic discharge. When nucleated, a $\mathrm{Ta}^{5+}$ phase gains possibility to grow using $\mathrm{Ta}^{5-x}$ compound crystals formed by electroreduction reaction (3) as a seed. Low conductivity of these crystals, which is related to low concentration of intercalation defects in the $\mathrm{CsTa}_{2+z}{ }^{5-x} \mathrm{O}_{5+y} \mathrm{~F}_{1-y}$ structure (Table 2) that makes possible such a performance.

Table 3

Phase compositions of cathodic products obtained at temperature $750{ }^{\circ} \mathrm{C}$ and $d_{\mathrm{c}}=0.15 \mathrm{~A} \mathrm{~cm}^{-2}$ in melts with various proportions $\mathrm{CsF}_{\text {in }}$ the solvents for $\mathrm{K}_{3} \mathrm{TaOF}_{6}$ (5 wt.\%)

\begin{tabular}{lccccc}
\hline $\begin{array}{l}\text { Mole fraction of } \mathrm{CsF} \text { in a } \\
\text { solvent for } \mathrm{K}_{3} \mathrm{TaOF}_{6}\end{array}$ & \multicolumn{4}{l}{ Phase composition of cathodic products (wt.\%) } \\
\cline { 2 - 6 } & $\alpha-\mathrm{Ta}$ & $\beta-\mathrm{Ta}$ & $\mathrm{CsTa}_{2+z} \mathrm{O}_{5+y} \mathrm{~F}_{1-y}$ & $\mathrm{TaO}$ & $\mathrm{UPh}-1$ \\
\hline 0 & 8 & 8 & 51 & 7 & 26 \\
0.5 & 22 & 58 & 12 & 0 & 0 \\
1 & 16 & 84 & 0 & 0 & 0 \\
\hline
\end{tabular}


Our tentative experiments using additions of caesium fluoride to the foregoing melts show (Table 3) that replacing of $\mathrm{CsCl}$ by $\mathrm{CsF}$ in solvents for $\mathrm{K}_{3} \mathrm{TaOF}_{6}$ leads to a considerable increase of metal phases proportion (especially $\beta-\mathrm{Ta}$ ) in cathodic products with corresponding diminution of $\mathrm{CsTa}_{2+z}{ }^{n+} \mathrm{O}_{5+y} \mathrm{~F}_{1-y}$ and other nonmetallic phases. Such phenomena can be associated with increase of solubility and the strength of tantalum oxyfluoride complexes as the amount of F-ions increases in the melt [22].

\section{Conclusions}

The basic regularities of variations in phase composition of cathodic products obtained in $\mathrm{CsCl}-\mathrm{K}_{3} \mathrm{TaOF}_{6}$ and $\mathrm{CsCl}-\mathrm{Cs}_{3} \mathrm{TaOF}_{6}$ molten systems at different electrolysis parameters have been established. Multiphase deposits are crystallized as a rule, and the number of phases inherent in one deposit can be as more as six suggesting that electrocrystallization nonequilibrium conditions for the most instances. Cathodic products can be formed both by a direct electrochemical reduction and through chemical reactions accompanying electrolysis process.

Unknown so far in the literature the low-valency tantalum compound $\mathrm{CsTa}_{2+2}{ }^{5-x} \mathrm{O}_{5+y} \mathrm{~F}_{1-y}$ with a pyrochlor-like crystal lattice is the most typical phase in electrolysis products in melts containing caesium cations. This compound was present in almost all obtained cathodic deposits. At the same time the conditions for electrodeposition only of pure, almost oxygenfree tantalum metal even from oxygen-containing melts were found.

The preparation by electrochemical way of $\mathrm{CsTa}_{2+z}{ }^{n+} \mathrm{O}_{5+y}$ $\mathrm{F}_{1-y}(n \leq 5)$ compounds in a single crystal form made it possible to examine special features of their structures. A number of resemblances and distinctions in structures of transparent dielectric crystals $(n=5)$ and metal-like conductive crystals $(n<5)$ have been revealed. It was found that the framework tantalum atoms are apparently not reduced during electrocrystallization, and the $\mathrm{Ta}_{\mathrm{int}}$ ions are only subjected to the electrochemical reduction. At the same time the framework anion composition is modified as a consequence of reduction process: the F/O ratio in mixed position $X=(O, F)$ is increased.

Earlier we have studied the phase composition of the cathodic products obtained by electrolysis in melts using lithium, sodium and potassium halides as solvents for $\mathrm{K}_{3} \mathrm{TaOF}_{6}$ and $\mathrm{K}_{3} \mathrm{TaO}_{2} \mathrm{~F}_{4}$ $[8,18,19]$. In contrast to the molten systems studied in the present work, tantalum oxide bronzes (hexagonal, tetragonal and cubic), but not compounds with pyrochlor type structure, have been crystallized in these melts besides tantalum metal and $\mathrm{TaO}$. The cause of this fundamental distinction can be as follows. In certain electrolysis conditions crystallization of tantalates and fluorotantalates take place in both cases. The $\left[\mathrm{TaO}_{3}\right]^{-}$framework of these compounds has cavities or channels whose dimensions correspond to the sizes of alkali metal ions neutralizing a charge of the framework. The $\mathrm{Cs}^{+}$cation is too large to be settled in channels of bronze type frameworks, and a pyrochlor framework with octahedral cavities is more appropriate for it; the distances
$\mathrm{M}-\mathrm{X}$, where $\mathrm{M}$ is an alkali metal, and $\mathrm{X}=(\mathrm{O}, \mathrm{F})$, are $3.05 \AA$ for $\mathrm{Cs}-\mathrm{O}$ and $2.0,2.35$ and $2.70 \AA$ for $\mathrm{Li}-\mathrm{O}, \mathrm{Na}-\mathrm{O}$ and $\mathrm{K}-\mathrm{O}$, respectively [23].

Preliminary results of $\mathrm{CsF}$ influence addition to $\mathrm{CsCl}-$ $\mathrm{K}_{3} \mathrm{TaOF}_{6}$ electrolytes on the phase composition of cathodic products have been obtained. The appreciable influence was found. This is a good reason for investigations in detail the processes in molten electrolytes with $\mathrm{CsF}$ as solvent for oxyfluorotantalate compounds. In contrast to chlorides, alkali metal fluorides dissolve well not only monooxyfluorides of tantalum (where $\mathrm{O} / \mathrm{Ta}=1)$, but also their dioxyfluorides $(\mathrm{O} / \mathrm{Ta}=2)$. That will permit to study chemical and phase compositions of cathodic products to be obtained at a higher oxygen content in melts.

\section{References}

[1] E. Christensen, X. Wang, J.H. von Barner, T. Østvold, N.J. Bjerrum, J. Electrochem. Soc. 141 (1994) 1212.

[2] F. Lantelme, Y. Berghoute, J.H. von Barner, G.C. Picard, J. Electrochem. Soc. 142 (1995) 4097.

[3] V.V. Grinevitch, A.V. Arakcheeva, E.G. Polyakov, S.A. Kuznetsov, Proceedings of the 11th International Symposium on Molten Salts, vol. 98-11, San Diego, CA, May 3-8, 1998, The Electrochem. Soc. Proceeding Series, Pennington, NJ, 1998, p. 84.

[4] V.I. Konstantinov, Electrolytic Preparation of Tantalum, Niobium and their Alloys, Metallurgiya, Moscow, 1977.

[5] V.V. Grinevitch, A.V. Arakcheeva, S.A. Kuznetsov, in: R.G. Rogers (Ed.), Green Industrial Applications of Ionic Liquids, NATO Series, II, vol. 92, Kluwer Academic Publishers, Amsterdam, 2003, p. 353.

[6] V.V. Grinevitch, A.V. Arakcheeva, S.A. Kuznetsov, V.T. Kalinnikov, Rus. Acad. Sci., Chem. 382 (2002) 47, Doklady (Reports).

[7] V.V. Grinevitch, A.V. Arakcheeva, S.A. Kuznetsov, J. Min. Metall. B 39 (2003) 223.

[8] V.V. Grinevitch, A.V. Arakcheeva, V.F. Shamray, S.A. Kuznetsov, Abstracts of EUCHEM 2002 Molten Salts Conference, Oxford, UK, September 1-6, 2002 (Abstract p. 64).

[9] W.G. Burgess, J.C. Basart, Z. Anorg. Allg. Chem. 216 (1934) 223.

[10] F. Frank, J.S. Kasper, Acta Cryst. 11 (1958) 184.

[11] K.W. Kwon, C. Ryn, R. Sinclair, S. Wong, Appl. Phys. Lett. 70 (1997) 3069.

[12] P.T. Moseley, C.J. Seabrook, Acta Cryst. B 29 (1973) 1170.

[13] V.V. Grinevitch, A.V. Arakcheeva, S.A. Kuznetsov, Proceedings of the International Symposium on Ionic Liquids, Carry le Rouet, France, June 26-28, 2003, p. 277.

[14] A.A. Arakcheeva, G. Chapuis, V.V. Grinevitch, Acta Cryst. B 58 (2002) 7.

[15] G. Brauer, H. Müller, G. Kühner, J. Less-Com. Met. 4 (1962) 533.

[16] D. Babel, G. Pausewang, W. Viebann, Z. Naturforsch. 22B (1967) 1219.

[17] J.B. Goodenough, H.-Y. Hong, J.A. Kafalas, Mater. Res. Bull. 11 (1976) 203.

[18] A.A. Arakcheeva, G. Chapuis, V.V. Grinevitch, V.F. Shamray, Crystallogr. Rep. 49 (2004) 70.

[19] A.A. Arakcheeva, G. Chapuis, V.V. Grinevitch, V.F. Shamray, Acta Cryst. B 57 (2001) 157.

[20] P. Chamelot, P. Palau, L. Massot, A. Savall, P. Taxil, Electrochim. Acta 47 (2002) 3423

[21] I. Barin, O. Knacke, Thermochemical Properties of Inorganic Substances, Springer, Berlin, 1973.

[22] D. Inman, S.H. White, J. Appl. Electrochem. 8 (1978) 375.

[23] R.D. Shannon, Acta Cryst. A 23 (1976) 751. 